\title{
Efektivitas Penerapan Teknik Clustering Terhadap Keterampilan Menulis Puisi Bebas Siswa Sekolah Dasar Gugus IV Kecamatan Biringkanaya Kota Makassar
}

\section{The Effectiveness of the Implementation of Clustering Techniques on the Free Poetry Writing Skill of Elementary School Students in Cluster IV, Biringkanaya District, Makassar City}

\author{
Sumarni ${ }^{1}$, Asdar $^{2}$, Sundari Hamid ${ }^{2}$ \\ ${ }^{1}$ Dinas Pendidikan Kota Makassar, Sulawesi Selatan \\ 2Program Studi Studi Pendidikan Dasar, Program Pascasarjana, Universitas Bosowa \\ E-mail: sumarnipendas@gmail.com
}

Diterima: 18 Agustus 2020/Disetujui 07 Desember 2020

\begin{abstract}
Abstrak. Penelitian ini bertujuan untuk mendeskripsikan keefektifan penerapan teknik Clustering, mengetahui gambaran keterampilan menulis puisi bebas siswa, menguji keefektifan penerapan teknik clustering terhadap keterampilan menulis puisi bebas siswa kelas V Sekolah Dasar Kelompok IV, Kecamatan Biringkanaya, Makassar. Penelitian ini merupakan penelitian kuantitatif dengan menggunakan desain eksperimen semu yaitu desain Nonequivalent Control Group Design. Dalam penelitian ini terdapat dua variabel yaitu variabel bebas penerapan teknik clustering dan variabel terikat adalah keterampilan menulis puisi bebas. Populasi penelitian ini adalah 121 siswa sekolah dasar kelompok IV Kecamatan Biringkanaya Makassar. Selanjutnya penentuan sampel menggunakan teknik cluster sampling yang terdiri dari kelompok atau cluster yaitu kelompok eksperimen dan kelompok kontrol yang masing-masing berjumlah 30 siswa. Instrumen pengukuran yang digunakan adalah tes, angket dan lembar observasi. Data yang diperoleh dianalisis dengan dua jenis statistik. Hasil analisis menunjukkan bahwa: (1) Efektivitas penerapan teknik clustering dalam pembelajaran bahasa Indonesia yang terdiri dari beberapa tahapan secara umum terlaksana dengan baik. (2) keterampilan menulis puisi bebas siswa SD kelompok IV di Kecamatan Biringkanaya Makassar dengan teknik clustering lebih tinggi yaitu 83,63 dibandingkan keterampilan menulis puisi bebas yang tidak menggunakan teknik clustering yaitu 76,27. (3) Penerapan teknik clustering dalam pembelajaran bahasa Indonesia efektif pada keterampilan menulis puis i bebas siswa kelas V kelompok IV Kecamatan Biringkanaya Makassar.
\end{abstract}

Kata Kunci: Teknik Clustering, Puisi Bebas, Keterampilan Menulis, Makassar

\begin{abstract}
This study aims to describe the effectiveness of the implementation of Clustering technique, to know the description of students' free poetry writing skill, to test the effectiveness of the implementation of the clustering technique toward free poetry writing skill of fifth grade students at Elementary School Group IV, Biringkanaya District, Makassar. This study is a quantitative study using a quasi-experimental design, namely the design of Nonequivalent Control Group Design. In this study, there are two variables: the independent variable is the implementation of clustering technique and the dependent variable is free poetry writing skill. The population of this study were 121 elementary school students in group IV, Biringkanaya District, Makassar. Furthermore, the number of sample is decided by using a cluster sampling technique that consists of groups or clusters, which are an experimental group and a control group, with 30 students each group. The instruments used were tests, questionnaires and observation sheets. The data obtained were analyzed by using two types of statistics. The results of the analysis show that: (1) the effectiveness of the implementation of clustering technique in Indonesian language learning which consists of several stages in general is well implemented; (2) the free poetry writing skill of elementary school students in group IV in Biringkanaya district, Makassar, with a clustering technique is higher, which is 83.63 compared to the free poetry writing skill of students who did not use a clustering technique, with only 76.27; (3) the implementation of clustering technique in Indonesian language learning is effective towards the free poetry writing skill of fifth-grade students in group IV, Biringkanaya district, Makassar.
\end{abstract}

Keywords: Clustering Technique, Free Poetry, Writing Skill, Makassar

\section{Pendahuluan}

Bahasa memiliki peran sentral dalam perkembangan intelektual, sosial, dan emosional peserta didik dan merupakan penunjang keberhasilan dalam mempelajari semua bidang studi. Keterampilan berbahasa mencakup empat komponen yaitu: (1) keterampilan menyimak, (2) keterampilan berbicara, (3) keterampilan membaca, (4) keterampilan menulis. Setiap 
keterampilan itu erat sekali hubungannya dengan tiga keterampilan lainnya. Di antara keempat keterampilan tersebut, keterampilan menulis dianggap sebagai keterampilan berbahasa yang paling sulit.

Pada dasarnya, semua keterampilan dalam bahasa Indonesia penting untuk dikuasai, tetapi menulis memang harus diakui sebagai sebuah aktivitas yang sangat berbeda bila dibandingkan dengan berbicara atau aktivitas verbal lainnya.

Menurut Tarigan dalam Sari (2013) menulis sebagai alat komunikasi tidak langsung. Sebuah tulisan penulis dapat menuliskan atau mendeskripsikan pemahamannya mengenai sesuatu hal, masalah, informasi yang ingin disampaikan oleh penulis. Tulisan juga dapat berfungsi sebagai petunjuk, memerintah, menyampaikan, mengingatkan, berkorespondensi dan memberi tahu.

Yosi Abdian Tindaon (2012) mendeskripsikan pentingnya kemampuan menulis yaitu: (1) Kegiatan menulis adalah satu sarana untuk menemukan sesuatu. Dalam artian, menulis dapat merangsang pemikiran dalam rangka mengangkat ide dan informasi yang ada di alam bawah sadar pemikiran. (2) Kegiatan menulis dapat memunculkan ide baru. (3) Kegiatan menulis dapat melatih kemampuan mengorganisasi dan menjernihkan berbagai konsep atau ide yang kita miliki. (4) Kegiatan menulis dapat melatih sikap objektif yang ada pada diri seseorang. (5) Kegiatan menulis dapat membantu diri kita untuk menyerap dan memproses informasi. (6) Kegiatan menuliskan memungkinkan kita untuk berlatih memecahkan beberapa masalah sekaligus. (7) Kegiatan menulis dalam sebuah bidang ilmu akan memungkinkan kita untuk menjadi aktif dan tidak hanya menjadi penerima informasi.

Abercrombie (dalam Busneni, 2017:2) juga menyatakan bahwa rasa takut musuh nomor satu dalam menulis. Abercrombie (2008: 157) menyatakan bahwa rasa takut dapat melumpuhkan seseorang sehingga orang itu hanya bisa memandangi kertas kosong atau layar computer saja. Ini memperkuat bahwa menulis tidak semudah yang kita bayangkan, dengan adanya ide untuk menulis namun ketika dituangkan kedalam secarik kertas terkadang kita menemukan kesulitan (Haryadi 1996).

Beberapa akar permasalahan itu mungkin yang mendasari mengapa tradisi menulis di kalangan para siswa masih dianggap lemah. Dalam hal ilmu pengetahuan di kalangan masyarakat, masih banyak yang beranggapan bahwa ilmu eksak (matematika, fisika, kimia, dll.) lebih menjanjikan sebuah harapan masa depan dibandingkan dengan ilmu-ilmu noneksakta (bahasa, sosial, dll.).

Menulis yang sesungguhnya termasuk dan lebih dekat ke ilmu noneksakta, terkena dampaknya. Bagi para siswa, tentunya lebih baik menghafal rumus-rumus matematika, fisika dll. yang lebih menjanjikan masa depan dibandingkan harus "corat-coret" membuat sebuah tulisan yang belum tentu hasilnya.

Berdasarkan uraian di atas dapat disimpulkan bahwa siswa kelas V SD gugus IV Kota Makassar mengalami kesulitan dalam belajar menulis puisi. Hal lain yang mempengaruhi rendahnya kemampuan menulis puisi siswa kelas V SD gugus IV Kota Makassar adalah strategi yang diterapkan oleh guru kurang bervariatif.

Berdasarkan uraian di atas, peneliti tertarik untuk melakukan penelitian dengan judul“ Efktivitas Penerapan Teknik Clustering Terhadap Keterampilan Menulis Puisi Bebas Bahasa Indonesia Siswa Kelas V SD Gugus IV Kota Makassar”.

\section{Metode Penelitian}

Penelitian ini menggunakan pendekatan kuantitatif dengan menggunakan metode quasi-eksperimen (Trijono, 2015). Kuasi eksperimen adalah penelitian yang menerapkan tindakan-tindakan yang diberi nama perlakuan (treatment).

1. Angket

Angket digunakan mengumpulkan data perhatian orang tua dan motivasi belajar. Penilaian angket menggunakan skala likert dengan kategori selalu (dilakukan setiap hari dalam seminggu), sering (dilakukan lebih dari 4 kali dalam seminggu), jarang (dilakukan kurang dari 4 kali dalam seminggu) dan tidak pernah (tidak pernah dilakukan dalam seminggu).

2. Dokumentasi

Dokumentasi digunakan untuk mengumpulkan data sekolah yang memuat:

a. Keadaan siswa dari setiap sekolah.

b. prestasi belajar nilai atau hasil belajar peserta didik dari masing-masing sekolah. tahun ajaran 2018/2019. Hasil belajar ini di peroleh dari nilai buku rapor siswa.

Uji analisis data yang digunakan berupa:

1. Uji deskriptif, untuk melihat sebaran data

2. Uji statistik inferensial, untuk mengetahui signifikansi menggunakan Uji T

Efesiensi relative $\emptyset_{2}$ terhadap $\emptyset_{1}$ dirumuskan

$$
\mathrm{R}\left(\varnothing_{2,}, \varnothing_{2}\right)=\frac{\mathrm{E}\left(\varnothing_{1-} \varnothing\right)^{2} \text { atau }}{\mathrm{E}\left(\varnothing_{1}-\varnothing\right)^{2}} \quad \frac{\operatorname{var} \emptyset_{1}}{\operatorname{var} \emptyset_{2}}
$$

Semua uji di atas menggunakan aplikasi SPSS versi 25.

\section{Hasil dan Pembahasan}

Hasil dalam penelitian ini menggunakan uji normalitas, uji homogenotas, uji hipotesis dan uji efektivitas dapat dilihat pada Tabel 1, Tabel 2, Tabel 3 dan Tabel 4 sebagai berikut: 
Tabel 1 Uji Normalitas

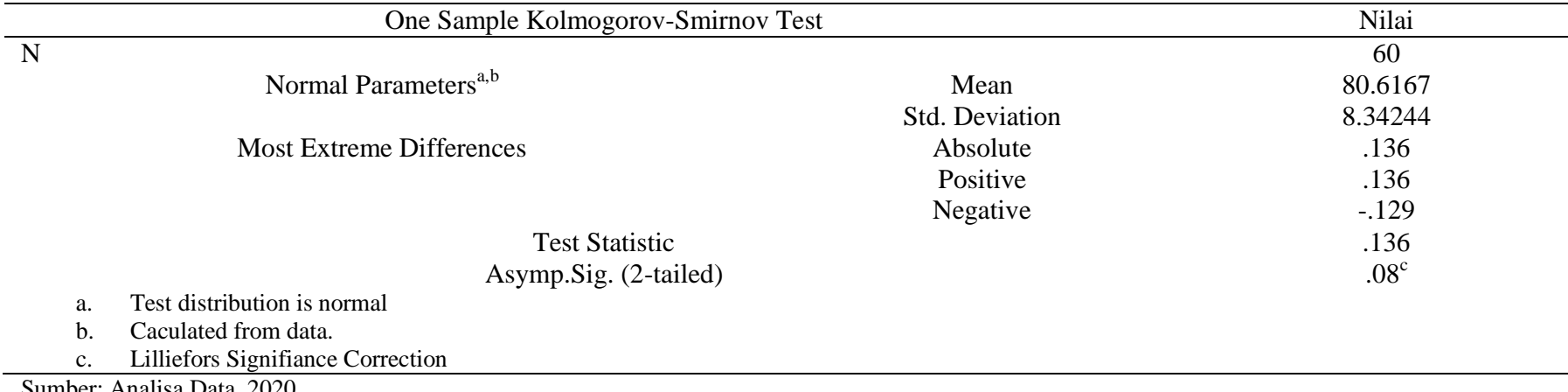

Dari data di atas diketahui bahwa data hasil pretest dan posttest berdistribusi normal. Itu dapat dilihat dari nilai sig yang lebih besar dari 0.05 yaitu 0.08 .

Tabel 2 Tes Homogenitas

\begin{tabular}{lcccc}
\hline & Test of Homogeity o Variance & & & df2 \\
& Levene Statistic & df1 & Sig. \\
\hline Based on Mean & .005 & 1 & 58 & .943 \\
Based on Median & .024 & 1 & 58 & .876 \\
Based on Median and with adjusted df & .024 & 1 & 45.584 & .877 \\
Based on trimmed mean & .002 & 1 & 58 & .961 \\
\hline
\end{tabular}

Sumber: Analisa Data, 2020.

Dari Tabel.2 dapat dilihat nilai sig semua berada di atas 0.05, sehingga dpat dikatakan semua data homogen.

Tabel 3. Independent Samples Test

\begin{tabular}{|c|c|c|c|c|c|c|c|c|c|}
\hline & \multicolumn{9}{|c|}{ t-test for Equality of Means } \\
\hline & \multirow{2}{*}{$\mathrm{F}$} & \multirow{2}{*}{$\begin{array}{l}\text { Sig } \\
\text {. }\end{array}$} & \multirow{2}{*}{$\mathrm{T}$} & \multirow{2}{*}{ Df } & \multirow{2}{*}{ Sig. (2- tailed) } & \multirow{2}{*}{$\begin{array}{c}\text { Mean } \\
\text { Difference }\end{array}$} & \multirow{2}{*}{$\begin{array}{l}\text { Std. Error } \\
\text { Difference }\end{array}$} & \multicolumn{2}{|c|}{$\begin{array}{c}95 \% \text { Confidence Interva } \\
\text { of the Difference }\end{array}$} \\
\hline & & & & & & & & Lower & Upper \\
\hline $\begin{array}{l}\text { Equal } \\
\text { Assumed }\end{array}$ & .005 & .943 & 2.983 & 58 & .004 & 5.03333 & 2. 02291 & 1.98405 & 10.08262 \\
\hline $\begin{array}{l}\text { Equal variances not } \\
\text { assumed }\end{array}$ & & & 2.983 & 57.575 & .004 & .03333 & 2.02291 & 1.98341 & 10.08325 \\
\hline
\end{tabular}

Dari Tabel 3 di dapat nilai dig sebesar 0.04, atau beradah di bawah 0.05 yang artinya terdepat signifikansi.

Tabel 4 Uji Efektivitas

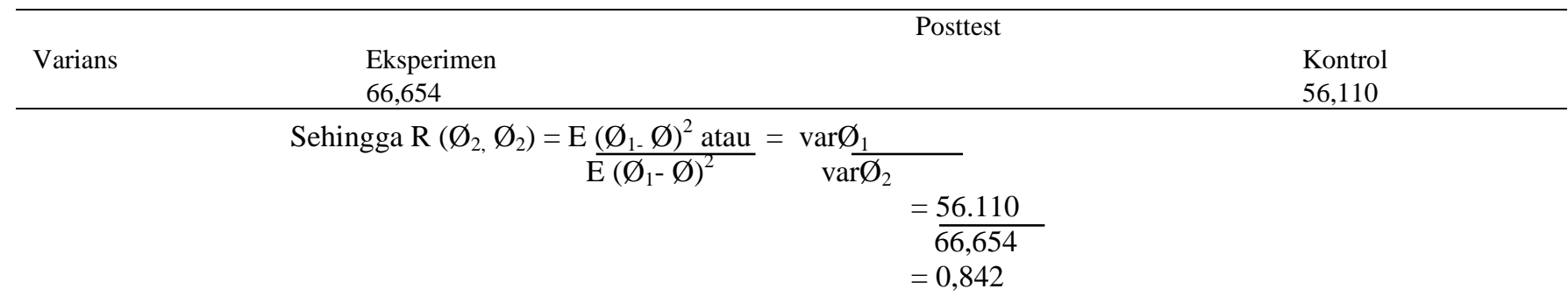

\section{Hakikat Pembelajaran Sastra Indonesia}

Pada hakikatnya belajar bahasa adalah belajar komunikasi. Oleh karena itu, pembelajaran bahasa Indonesia diarahkan untuk meningkatkan kemampuan siswa dalam berkomunikasi dengan bahasa Indonesia, baik secara lisan maupun tulisan. Sedangkan pembelajaran sastra dimaksudkan untuk meningkatkan kemampuan siswa mengapresiasi karya sastra. Kegiatan mengapresiasi sastra berkaitan erat dengan latihan mempertajam perasaan, penalaran, dan daya khayal serta kepekaan terhadap masyarakat, budaya dan lingkungan hidup.

Pembelajaran sastra dipandang penting dalam pembinaan kehidupan manusia. Sutjarso (2006: 5) menekankan dengan menguraikan kedudukan penting sastra dalam membina kehidupan manusia. Pertama, dalam karya sastra diceritakan tentang kehidupan cikal-bakal tentang kesaktian dan kemuliaan. Dalam hal ini, peserta didik harus diarahkan untuk menangkap nilainilai dalam tokoh pada cerita yang diarahkan oleh pendidik. Kedua, integritas dan stabilitas sosial serta kelestarian pranata dan budaya dapat dijaga karena sastra mengandung petunjuk tentang hal yang boleh dilakukan dan yang tidak boleh dilakukan. Terakhir, sastra memuat cerita petualangan, percintaan, dan peperangan yang memikat dan menegangkan dengan gaya bahasa yang estetis.

\section{Keterampilan Menulis}

Keterampilan menulis merupakan salah satu jenis keterampilan berbahasa yang harus dikuasai siswa. Banyak ahli telah mengemukakan pengertian menulis. Menurut pendapat Suparno (2007: 129) keterampilan menulis adalah kemampuan 
mengungkapkan gagasan, pendapat, dan perasaan kepada pihak lain dengan melalui bahasa tulis. Ketepatan pengungkapan gagasan harus didukung dengan ketepatan bahasa yang digunakan, kosakata dan gramatikal dan penggunaan ejaan. Menurut Ahmad Rofi'uddin dan Darmiyati Zuhdi (1999: 159), keterampilan menulis merupakan suatu keterampilan menuangkan pikiran, gagasan, pendapat tentang sesuatu, tanggapan terhadap suatu pernyataan keinginan, atau pengungkapan perasaan dengan menggunakan bahas tulis.

Keterampilan menulis puisi adalah keterampilan berekspresi. Dalam menulis puisi sangat menonjolkan penekanan pada ekspresi diri secara pribadi. Selain itu, menulis puisi juga menekankan pengekspresian emosi, gagasan atau Simpulan yang dapat diambil didasari uraian di atas yaitu bahwa menulis puisi merupakan wujud komunikasi tidak langsung (bahasa tulis) yang menekankan pada ekspresi diri, emosi, gagasan dan ide. Selain itu, keterampilan menulis puisi merupakan proses aktivitas berpikir manusia secara produktif dan ekspresif serta didukung oleh proses pengetahuan, kebahasaan, dan teknik penulisannya.

\section{Clustering (Pengelompokan)}

Clustering (pengelompokan) adalah suatu cara memilah gagasan-gagasan dan menuangkannya ke atas kertas secepatnya tanpa mempertimbangkan kebenaran atau nilainya (DePoretr, 2009: 180). Pengelompokan yang dilakukan dengan menuliskan kata-kata di atas kertas mengikuti proses berpikir yang terjadi di dalam otak. Jika menggunakan teknik pengelompokan untuk merangsang gagasan dalam proyek penulisan akan membantu memberikan titik awal rencana yang akan ditulis (Hernowo, 2008). Teknik Clustering adalah teknik menulis yang mengalir bebas dan mengedepankan aspek spontanitas tanpa melakukan proses penyuntingan dalam menuangkan gagasan, sehingga tulisan yang dihasilkan tidak akan sempurna, tetapi juga tidak akan kaku dalam bahasa.

\section{Kesimpulan dan Saran}

Hasil penelitian dapat disimpulkan bahwa keterampilan menulis puisi bebas Bahasa Indonesia siswa kelas V SD Inpres Kalang Tubung I yang diajar tanpa menggunakan teknik clustering atau kelas control diperoleh nilai rata-rata hasil belajar pretest 73,17 dan posttest 77,60. Hasil belajar keterampilan menulis puisi bebas Bahasa Indonesia siswa kelas V SD Inpres Laikang yang diajar menggunakan teknik clustering atau kelas eksperimen diperoleh nilai rata-rata hasil belajar pretest 76,27 dan posttest 83,63, dengan kata lain menglami peningkatan. Pembelajaran Bahasa Indonesia Khususnya menulis puisi bebas untuk menerapkan teknik clustering, Kepada pihak sekola agar memfasilitasi diterapkannya teknik clustering, sehingga guru mampu menerapkan teknik pembelajaran sesuai dengan dengan kondisi siswa untuk meningkatakan hasil belajar Bahasa Indonesia siswa. Kepada calon peneliti berikutnya agar teknik clustering digunakan pada sekolah yang hasil belajar keterampilan menulis puisi bebas Bahasa Indonesia masih kurang.

\section{Daftar Pustaka}

Abercrombie. 2008. The Penguin Dictonary of Sociology. London: Penguin Books.

Ahmad Rafiuddin \& Darmiyati. 1999. Pendidikan Bahasa dan Sastra Indonesia di Kelas Tinggi. Jakarta: Dirjen Dikti, Depdikbud.

Busneni (2017) Penerapan Teknik Clustering dalam Bahasa Indonesia terhadap Keterampilan Menulis Teks Siswa Kelas V SD Inpres Layang Tua 1 Makassar, Tesis, Makassar: Universitas Negeri Makassar.

De Porter dan Hernacki. 2009. Quantum Learning: Membiasakan Belajar Nyaman dan Menyengkan. Bandung: Kaifa.

Gie The Liang, 2002. Terampil Mengarang. Yogyakarta: ANDI

Guru, Tuan. 2012. Teknik Tes dan Nontes dalam Evaluasi. Online http://tuanguru.com/2012 diakses Februari 2019.

Haryadi, Zamzani (1996/1997) Peningkatan Keterampilan Berbahasa Indonesia. Jakarta: Dirjen Dikti

Jabrohim, dkk. 2009. Cara Menulis Kreatif. Yogyakarta: pustaka Pelajar.

Jainuddin, J., \& Sirajuddin, S. (2020). Pengaruh Minat dan Kedisiplinan Siswa dengan Gaya Kognitif Field Indefendent terhadap Hasil Belajar Matematika Siswa SMK Farmasi Yamasi Makassar. Delta-Pi: Jurnal Matematika dan Pendidikan Matematika, 9(2).

Jainuddin, J. (2019). Peningkatan Hasil Belajar Matematika Melalui Latihan Menyelesaikan Soal Secara Sistematis Pada Siswa Kelas XI. IPA1 Sma Negeri 2 Sungguminasa. Klasikal: Journal Of Education, Language Teaching And Science, 1(3), 44-52.

Kusumawati Heny. 2017. Tema 8 Lingkungan Sahabat Kita. Jakarta: Pusat Kurikulum dan Perbukuan, Balitbang, Kemdikbud.

Mahmudah, 2011. Pengajaran Puisi. Makassar: UNM

Sari Kumala Intan dkk, 2013. Penerapan Model Quantum Learning dengan Teknik Peneglompokan (Clustering) untuk Meningkatkan Kemampuan menulis Puisi pada Siswa Sekolah Dasar. Jurnal. Surakarta, Universitas Sebelas Maret Surakarta.

Sulastriningsih dan Mahmudah. 2007. Pengajaran Prosa Fiksi dan Drama. Makassar: UNM.

Suparno. 2007. Keterampilan Dasar Menulis. Jakarta: UT 